\title{
An obesity therapeutic treatment as a modern pharmaceutical industry challenge
}

Keywords: obesity, pharmacological treatment, anti-obesity drugs, saxenda, QSYMIA, VIVUS, orexigen, lorcaserin, BELVIQ, GLP1 receptor agonist

\section{Introduction}

Obesity is the serious risk factor for different pathological health condition, and recognized as 5th leading death risk among of global population. ${ }^{1}$ In 2020, it was estimated 5million deaths worldwide were attributable to diabetes, obesity and their complications. ${ }^{2}$ It is also a high risk factor for diabetes, microvascular and cardiovascular diseases, and its occurrence correlates with obesity/overweight positively. ${ }^{3}$ In addition to the health effects, obesity imposes significant external costs on society. For example, in the United States alone, annual medical expenditures for treating obesity-related health conditions now exceed \$147billion per year, with roughly half of this total directly financed by Medicare and Medicaid. ${ }^{4-7}$

A problem of obesity contains a complex of behavioral, genetic and social related factors that determined the difficulty of successful medical correction and intervention of this pathology. Traditionally, weight reduction was relaying on changing a life style and physical activity. ${ }^{8}$ The problem of compliance and consistency of nonmedicament therapy of obesity is the well-known limiting factor (Bray)Previous studies demonstrated that medicament therapy as Orlistat is more effective in weight reduction than life style modification and physical activity. ${ }^{9}$

FDA approved several anti-obesity agents recently. AACE included obesity as a pathology to cure by medicine therapy adjunct to a life style modification. The problem is very complex because it is based on several factors of pathogenesis as behavior, genetic predisposition, activity of metabolism and hormonal balance. It is the main cause that there are only 3 approved by FDA anti-obesity drugs on a market (it is probably going to be 4 this fall) and all of them have a different mechanism of action, possible adverse effects and modest efficacy on compare with surgical procedures. It is way to go to the truly potent, completely safe and sufficient medicament to treat obesity as a disease.

Lorcaserin (BELVIQ ${ }^{\circledR}$ ) Eisai Inc was approved by FDA in 2012, after rejection in 2010, as a specific 5-HT2c , serotonin receptor agonist, mobilized to modify behavior by blocking a hunger feeling. The drug has unboxed warning of adverse effects (AEs) related mostly with serotonin toxicity. Eisai published results of 3 phaseIII studies for the FDA expert board review and prescription information. Approximately $47 \%$ of non-diabetic patients lost more than $5 \%$ of weight, when T2DM patients lost $37 \%$ body weight in 52 weeks. Besides weight lost, HbAlc and FPG statistically significant reduction in T2DM patients compare with placebo was reported in BLOOm study. A severe hypoglycemia reported twice more often than comparator, when moderate hypoglycemia cases were as often as in the placebo group. ${ }^{10,11}$

Phentermine/topiramate (QSYMIA®) also was approved in 2012 by FDA. ${ }^{12}$ It is combined drug with immediate-release phentermine
Volume 2 Issue 5 - 2015

Sergey B Zhuplatov

Department of Medical Affairs, Astrazeneca co.pt, USA

Correspondence: Sergey B Zhuplatov, Department of Medical Affairs, Astrazeneca co.pt, USA, Tel 801-696-4394, Email Joesergey@yahoo.com

Received: May 08, 2015 | Published: July 20, 2015

hydrochloride (PHEN) and extended-release topiramate (TPM). Mechanism of action (MOA) is based on simpatomimetic release of norepinephrine and dopamine in the hypothalamus (PHEN) and anticonvulsant inhibition of sodium, $\mathrm{Ca}$ and GABA-A receptors (TPM). The drug has non-boxed warning, related to different neurological side effects, but fewer cognitive side effects reported for the combined drug in compare with topiramate alone. Approximately $66 \%$ patients on a high dose of QSYMIA ${ }^{\circledR}$ lost weight more than $5 \%$ in compare with $15.5 \%$ patients from placebo group, according to full prescription information. The drug is approved for a short term use and prescribers may be monitored by state Medical boards ${ }^{13}$ (Table 1) (Table 2)

The third combined anti-obesity drug, approved by FDA just recently in September 2014 is naltrexone SR/buproprion SR (CONTRAVE®). ${ }^{14}$ Combination of Naltrexone as an opioid antagonist, which block opioid receptor-medicated POMC autoinhibition, and buproprion as an aminoketone antidepressant that stimulates hypothalamic POMC neurons, are designed to influence the hypothalamus in order to decrease food intake over an extended period of time. CONTRAVE® has a boxed warning related to buproprion as antidepressant that has an increased risk of suicidal thoughts and neurothoxic reactions. Almost 56\% patients from treatment group lost more than $5 \%$ of weight in CORII 3 phase trail versus $17.5 \%$ in placebo group ${ }^{14}$ (Table 1) (Table 2).

Liraglutide $3 \mathrm{mg}$ Saxenda ${ }^{\circledR}$ is the first an anti- obesity drug from GLP-1 receptor agonists class. $81.6 \%$ patients on Liraglutide $3 \mathrm{mg}$ lost more than $5 \%$ weight in reported by Novo Nordisk studies, ${ }^{15}$ which is comparable with study results for QSYMIA. In general, all GLP1 receptor agonistshave significant weight reduction from baseline comparable with other anti-obesity drugs, but incretins have different adverse effects profile, which reflected mostly in GI-tract adverse events as nausea, vomiting, etc. Liraglutide have pancreatitis and C-cell tumor risk warning in the prescription information ${ }^{16}$ (Table 2).

The meta-analysis of Zhang and coauthors ${ }^{17}$ involved 1345 individuals who completed studies, and their mean BMIs varied from 31.9 to $41.3 \mathrm{~kg} / \mathrm{m}^{2}$. When liraglutide of high dose $(3.0 \mathrm{mg} /$ day $)$ compared with placebo in a random effect meta-analysis, the mean weight reduction of participants in the GLP-1RA group was much higher than that in the controls $(-5.14 \mathrm{~kg}, 95 \% \mathrm{CI}-6.61$ to $-3.67 ; \mathrm{Z}=$ 6.86, $\mathrm{P}<0.00001) .{ }^{17}$ 


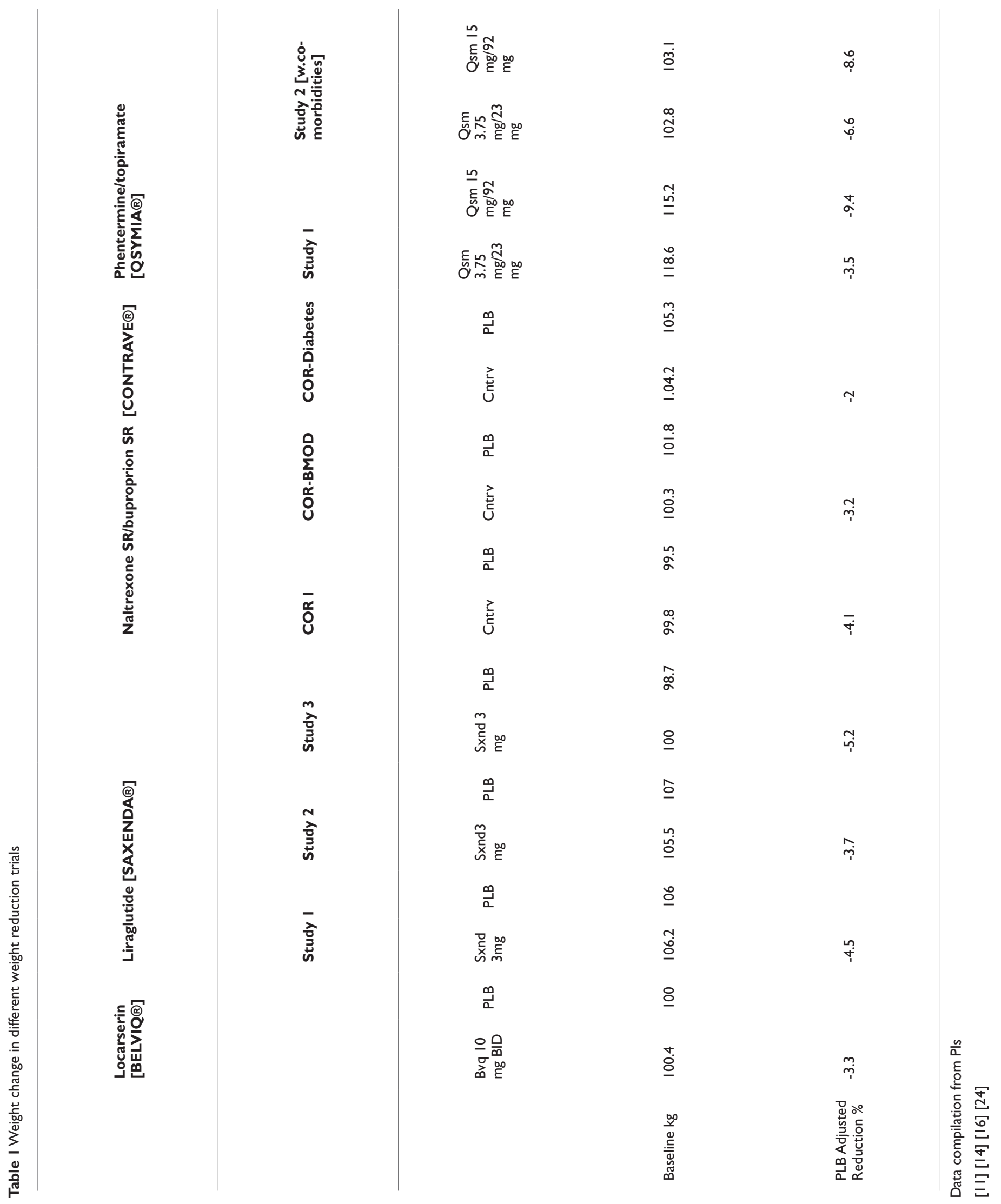


Table 2 Secondary endpoint, structure of adverse effects and warnings in a prescription information for weight reduction therapy agents

\begin{tabular}{|c|c|c|c|c|}
\hline & $\begin{array}{l}\text { Locarserin } \\
{\left[\text { BELVIQ }{ }^{\circledR}\right]}\end{array}$ & $\begin{array}{l}\text { Phentermine/Topiramate } \\
\left.\text { [QSYMIA }{ }^{\circledR}\right]\end{array}$ & $\begin{array}{l}\text { Naltrexone SR/Buproprion SR } \\
\text { [CONTRAVE }^{\circledR} \text { ] }\end{array}$ & Liraglutide [SAXENDA ${ }^{\circledR}$ ] \\
\hline $\begin{array}{l}\text { Patients Lost } \\
5 \% \text { Weight }\end{array}$ & 47.2 & $67 \%$ & $50.5 \%$ & $81.6 \%$ \\
\hline AEs & $\begin{array}{l}\text { Neurological } \\
\text { disorder }\end{array}$ & $\begin{array}{l}\text { Fetal toxicity, psychiatric and } \\
\text { neurological disorder, High HR, } \\
\text { Hypoglycemia }\end{array}$ & $\begin{array}{l}\text { Depression and suicidal thoughts, } \\
\text { Seizure, Hepatotoxicity, Glaucoma, } \\
\text { Hypoglycaemia }\end{array}$ & $\begin{array}{l}\text { Gl- tract reaction, pancreatitis, C-cell } \\
\text { tumours in animals, Hypoglycemia }\end{array}$ \\
\hline Warning in PI & Not boxed & Not boxed & $\begin{array}{l}\text { Boxed for Suicidal Thoughts And } \\
\text { Behaviours;And Neuropsychiatric } \\
\text { Reactions }\end{array}$ & $\begin{array}{l}\text { Boxed for Risk OfThyroid C-Cell } \\
\text { Tumors }\end{array}$ \\
\hline
\end{tabular}

Data compilation from Pls

[16] [11] [14] [24] [12]

One thousand three hundred forty five individuals retrieved from eight studies were involved and all included trials were of mild-tomoderate bias risks (Novo Nordisk, 2014). Participants in GLP-1RA groups achieved a larger weight loss than those in control groups $(-2.85 \mathrm{~kg}, 95 \% \mathrm{CI}-3.55$ to -2.14$)$, and liraglutide may work in a dosedependent fashion. GLP-1RAs also reduced body mass index (BMI) and waist circumferences (WC) and benefited systolic blood pressure and triglyceride regulation. However, GLP-1RAs were associated with increased nausea and vomiting events. ${ }^{16}$

Despite to all successful approval by FDA, all anti-obesity prescription drugs on the US market have relatively "modest" efficacy in weight reduction comparatively to surgical treatment, as a bariatric surgery. ${ }^{18}$ QSYMIA has the biggest placebo adjusted weight reduction as $9.4 \%$ from the body weight during 52 weeks trial, CONTRAVE and SAXENDA are very close by results each other by $5.2 \%$ and $5.8 \%$ placebo adjusted weight reduction, respectively, when Belviq reduced weight to $3 \%$ in 52 weeks (Table1). At the same time, all oral or surgical weight reduction options have adverse effects that could limit a wide use of these methods in a Medical practice (Table 1) (Table 2).

The approach to modulation of CNS peptide pathways could be promising. Investigators looking for safe and effective ways to inhibit hunger, increase satiety without followed adverse effects. Some interesting results obtained from research of NPY antagonists, ${ }^{19,20}$ melanin concentrating hormone (MSH) receptor antagonists ${ }^{21}$ and melanocyte stimulants lately. ${ }^{20}$ As an example,ARC NPY neurons mediate hyperphagia and obesity in the ob/ob and $\mathrm{db} / \mathrm{db}$ mice and fa/ fa rat, in which leptin inhibition is lost through mutations affecting leptin or its receptor. Antagonists of the Y5 receptor (currently thought to be the NPY 'feeding' receptor) have anti-obesity effects. ${ }^{20}$ Some authors do discuss the effectiveness of NPYY5 receptors inhibition, as a possible anti-obesity treatment approach. ${ }^{19}$ The treatment with the MCH1 receptor antagonist at 30mg.kg (-1) for 1 month moderatelysuppressed feeding and significantly reduced body weight by $24 \%$ in a rodent model. ${ }^{21}$ Other pathway in obesity treatment research is the investigation of adipose tissue and gut hormones as PYY3-36, ${ }^{22}$ oxyntomodulin, ${ }^{9,23}$ ghrelin, ${ }^{23}$ leptin and GLP-1RA. ${ }^{23}$ Evidently, administration of PYY(3-36) resulted in increased ratings of satiety and decreased ratings of hunger, thirst, and prospective food consumption..$^{22}$ Gut hormones acutely modulated the peptidergic pathways, resulting in a stimulation hunger effects by ghreline, or in an inhibition effects by PYY and oxintomoduline. ${ }^{23}$

\section{Acknowledgements}

None.

\section{Conflict of interest}

The author declares no conflict of interest.

\section{References}

1. WHO. Obesity: preventing and managing the global epidemic. Report of a WHO Consultation (WHO Technical Report Series 894) Geneva; 2000. p. 1-252.

2. Lund A, Knop FK, Vilsbøll T. Glucagon-like peptide-1 receptor agonists for the treatment of type 2 diabetes:Difference and similarities. Eur J Intern Med. 2014;25(5):407-414.

3. Sharma MD, Garber AJ. What is the best treatment for prediabetes? Curr Diab Rep. 2009;9(5):335-341.

4. Finkelstein EA, Trogdon JG, Cohen JW, et al. Annual medical spending attributable to obesity:payer- and service-specfic estimates. Health Aff. 2009;28(5):w822-w831.

5. NH\&LI, NIH. Clinical guidlines on the identification, evaluation and treatment of overweight and obesity in adults. NIH. Washington DC: NIH publication; 1998. p. 4083-4098.

6. Snow V, Barry P, Fitterman N, et al. Pharmacologic and surgical management of obesity in primary care:A clinical practice guideline from American College of Physicians. Ann Intern Med. 2005;142(7):525531

7. Wu Y. Overweight and obesity in China. BMJ. 2006;333(7564):362363.

8. Steig AJ, Jackman MR, Giles ED, et al. Exercise reduces appetite and traffics excess nutrients away from energetically efficient pathways of lipid deposition during the early stages of weight regain. Am J Physiol Regul Integr Comp Physiol. 2011;301(3):R656-R667.

9. Bray GA. Medical treatment of obesity:The past, the present and the future. Best Pract Res Clin Gastroenterol. 2014;28(4):665-684.

10. Woodcliff Lake NJ. Lorcaserin hydrochloride briefing document NDA 22529 for FDA Advisory Committee. Eisai Inc; 2012.

11. Zofingen. BELVIQ Full Prescription Information. Arena Pharmaceuticals $\mathrm{GmbH} ; 2012$. 
12. VIVUS, Inc. QSYMIA (phentermine and topiramate extended-release) capsules, for oral use, CIV Prescription Information. USA: Vivus, Inc; 2012

13. VIVUS Inc. Phentermine/topiramate briefing document NDA 22580 for FDA Advisory Committee. Mountain View, VIVUS Inc; 2012.

14. La Jolla CA. Contrave Full Prescription Information. Prescription information, Orexigen Therapeutics, Inc; 2014.

15. Novo Nordisk. Liraglutide injection $3 \mathrm{mg}$ briefing document NDA 206321 for FDA Advisory Committee; 2014.

16. SAXENDA (2014) (liraglutide [rDNA origin] injection), solution for subcutaneous use Prescription Information.

17. Zhang F, Tong Y, Su N, et al. Weight loss effect of glucagon-like peptide-1 mimetics on obese/overweight adults without diabetes:A systematic review and meta-analysis of randomized controlled trials. J Diabetes. 2005;7(3):329-339.

18. Buddeberg-Fischer B, Klaghofer R, Krug L, et al. Physical and Psychosocial Outcome in Morbidly Obese Patients with and without Bariatric Surgery:a 41/2-Year Follow-up. Obes Surg. 2006;16(3):321-330.
19. Levens NR, Della-Zuana O. Neuropeptide Y Y 5 receptor antagonists as anti-obesity drugs. Curr Opin Investig Drugs. 2003;14(10):1198-2004.

20. Williams G, Harrold JA, Cutler DJ. The hypothalamus and the regulation of energy homeostasis:lifting the lid on a black box. Proc Nutr Soc. 2000;59(3):385-396.

21. Ito M, Ishihara A, Gomori A, et al. Mechanism of the anti-obesity effects induced by a novel Melanin-concentrating hormone 1-receptor antagonist in mice. Br J Pharmacol. 2010;159(2):374-383.

22. Sloth B, Davidsen L, Holst JJ, et al. Effect of subcutaneous injections of PYY1-36 and PYY3-36 on appetite, ad libitum energy intake, and plasma free fatty acid concentration in obese males. Am J Physiol Endocrinol Metab. 2007;293(2):E604-E609.

23. Loviselli A, Secci G, Lai A, et al. Mechanisms of regulation of the food intake:recent advances. Recenti Prog Med. 2007;98(1):1-6.

24. Deerfield IL. CONTRAVE (naltrexone $\mathrm{HCl}$ and bupropion $\mathrm{HCl}$ ) Extended-Release Tablets. Prescription Information. Takeda Pharmaceuticals America, Inc. Diabetes; 2014. p. 1635-1639. 